\title{
Tumor de células redondas en un perro de 7 meses
}

\author{
Galán Torres JA. ${ }^{1}$, Ortega García M ${ }^{\mathrm{a}}{ }^{2}{ }^{2}$
}

Sanid. mil. 2012; 68 (3): 185-186; ISSN: 1887-8571

Perro mestizo de 7 meses de edad, que presenta un nódulo en botón en región malar izquierda de unos 0,7 cm de diámetro, de superficie depilada. Tras la extirpación se procede a su estudio histopatológico.
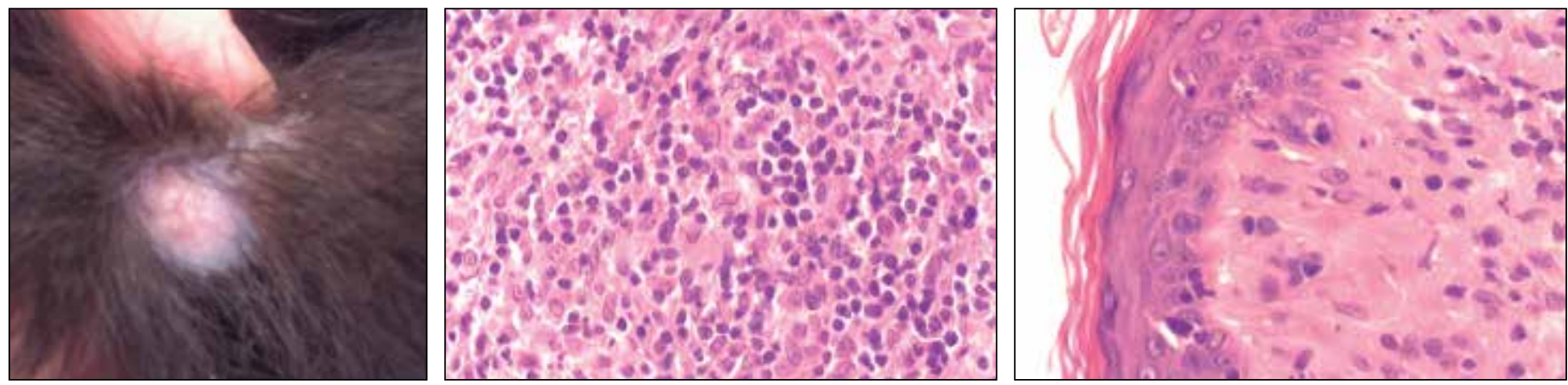

Figura 1. Aspecto macroscópico del Figura 2. Se aprecia infiltrado de células linfo- Figura 3. Margen subcutáneo de la lesión. Célunódulo, que aparece depilado y bien citarias en la masa tumoral. En el centro de la las dispersas que respetan la epidermis y pequedelimitado. preparación se observa un núcleo de forma arri- ñas zonas de regresión espontánea. H-E. $200 x$. ñonada. H-E.200x.

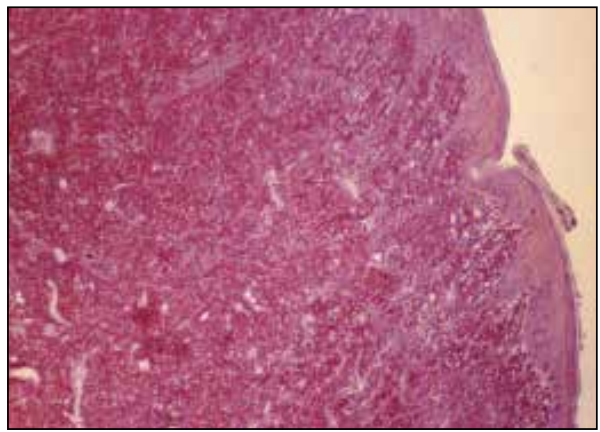

Figura 4. Tinción positiva a vimentina. $100 x$.
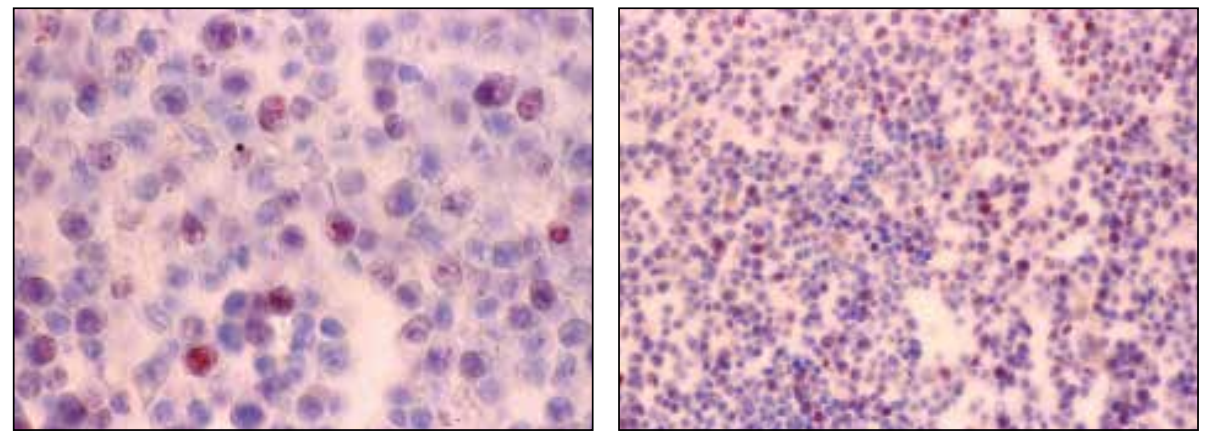

Figuras 5 y 6. Inmunotinción para el antígeno nuclear de proliferación celular Ki-67. Muchas células presentan tinción positiva. Contraste con hematoxilina. 100x y 600x.

\section{ESTUDIO HISTOPATOLÓGICO}

Se aprecian células neoplásicas redondas y poligonales dispuestas en cordones y masas densas y que presentan citoplasmas acidófilos y finamente granulares, grandes núcleos con distribución cromática uniforme, -algunos en forma arriñonada o en «C», y nucléolos solitarios-, que infiltran el tejido circundante y obliteran completamente las estruc- turas anexas, pero respetando la epidermis. Puede existir ulceración ${ }^{1}$ También se observan células linfocitarias y zonas degenerativas de reabsorción. En la zona superficial, bajo la epidermis, las células se disgregan formando cordones perpendiculares a la superficie de la misma. Las mitosis son frecuentes ${ }^{2}$. Se realiza inmunotinción para antígeno de proliferación nuclear Ki-67 para poner de manifiesto su actividad celular, y también para vimentina.

${ }^{1}$ Tcol. Veterinario. Centro Militar de Veterinaria. Servicio de Microbiología, Higiene y Sanidad Ambiental. Madrid. España.

${ }^{2}$ Cap. Veterinario. Instituto Tecnológico «La Marañosa». Madrid. España.

Dirección para correspondencia: Centro Militar de Veterinaria de la Defensa. Servicio de Microbiología, Higiene y Sanidad Ambiental. C/ Darío Gazapo, 3. 28024 Madrid. jgaltor@ oc.mde.es

Recibido: 22 de marzo de 2012

Aceptado: 24 de julio de 2012 


\section{Diagnóstico: Histiocitoma}

Los histiocitomas son tumores frecuentes en perros, representando el $19 \%$ de todas las neoplasias de piel y tejido subcutáneo. Su etiología es desconocida pero se asemeja más a una hiperplasia reactiva que a un verdadero tumor. Los histiocitomas derivan de la línea celular de los monocitos-macrófagos, o incluso de células de Langerhans, según el resultado de técnicas inmunohistoquímicas y de microscopía electrónica.

Los histiocitomas presentan un crecimiento rápido, de aspecto fungoso, alopecia y tamaño de 0,5 a 1,5 cm de diámetro, aunque en ocasiones pueden ser mayores o múltiples. La gran mayoría aparecen en animales menores de 3 años y afectan a cualquier raza, aunque algunas puras pueden presentar cierta predisposición, se localizan en cualquier lugar del cuerpo, principalmente en hocico, pabellón auricular, extremidades y escroto. Es frecuente la regresión espontánea ${ }^{3}$. Se cree que el perro se hace inmune después del desarrollo del tumor. Es raro en gatos.

El diagnóstico diferencial del histiocitoma cutáneo canino es limitado; en estadios regresivos con difusa infiltración linfocitaria puede ser difícil detectar histiocitos residuales típicos. Las lesiones pueden confundirse con dermatitis focales inducidas por picaduras de artrópodos. La diferenciación entre histiocitoma y linfoma cutáneo de células $T$ en muestras de lesiones de perros viejos puede ser problemática. Los histiocitomas suelen ser solitarios y los linfomas cutáneos normalmente multicéntricos, pero puede ocurrir lo contrario en algunas ocasiones. Los histiocitomas caninos son positivos a vimentina y, ocasionalmente, a lisozyma; y negativos a S-100.

\section{TRATAMIENTO}

El más utilizado es la escisión quirúrgica convencional, también se emplea la criocirugía, electrocirugía e, incluso, la observación sin tratamiento. La mayoría de estas neoplasias involucionan espontáneamente en unos tres meses. Responden bien a la administración tópica de corticoides en dimetil-sulfóxido ${ }^{1,2}$.

\section{BIBLIOGRAFÍA}

1. Medleau L, Hnilica KA. Dermatología de pequeños animales. Atlas en color y guía terapéutica. $2^{\mathrm{a}}$ ed. Elsevier. 2007; pp. 431-436.

2. Scott DW, Miller WH, Griffin CE. Small animal dermatology. W. B. Saunders Company. 2001; pp. 1.347-1350.

3. Gross TL, Ihrke PJ, Walder EJ. Veterinary dermatopathology. Mosby Year Book. 1992; pp. 465-468 